\title{
Papers
}

\section{How fundraising is carried out in US nonprofit organisations}

\author{
Mark Hager*, Patrick Rooney and Thomas Pollak \\ *Center on Nonprofits and Philanthropy, The Urban Institute, 2100 M Street NW, \\ Washington DC 20037, USA; Tel: +1 202261 5345; Fax: +1 202833 6231; \\ e-mail: mhager@ui.urban.org
}

Received: 21st August, 2002

Mark Hager PhD is a research associate in the Center on Nonprofits and Philanthropy at the Urban Institute in Washington DC. In addition to his ongoing collaborative work on nonprofit fundraising and administrative costs, he also has a research interest in arts organisations and the role of the arts in communities.

Patrick Rooney has been Director of Research for the Center on Philanthropy at Indiana University since 1999. For almost six years, he served both as special assistant to the Indiana University Vice-President for Long-Range Planning and Chancellor of Indiana University-Purdue University Indianapolis (IUPUI), and as Assistant Dean for Academic Programmes for Indiana University-Purdue University Columbus (Ind.).

Rooney guides all Center research activities, including its signature research project, a longitudinal study of giving and volunteering, a collaborative study with the Urban Institute on the cost of fundraising and overhead, the research for 'Giving USA', and the Center's semiannual Philanthropic Giving Index, which reports and predicts the climate for charitable giving.

Thomas Pollak JD is Senior Research Associate of the Center on Nonprofits and Philanthropy, The Urban Institute, Washington, DC. In this capacity, he serves as Assistant Director of the National Centre for Charitable Statistics, the national repository of data on the nonprofit sector in the USA.

\begin{abstract}
A substantial number of nonprofit organisations in the USA report inflows of charitable contributions or grants without expenditures allocated to fundraising costs. This observation raises questions about how fundraising is carried out. Based on a survey of US charities, the paper observes that nonprofit organisations use a range of internal capacities and external relationships to conduct their fundraising. The use of staff members dedicated to fundraising is common, but much fundraising is still carried out by executive directors, volunteers and board members. Also, a substantial number of organisations engage external entities, including federated campaigns, support organisations and professional fundraising firms to generate contributions.
\end{abstract}

\section{INTRODUCTION}

Nonprofit organisations in the USA attract grants and contributions in a variety of ways. Some rely on mail or
International Journal of Nonprofit and Voluntary Sector Marketing, Vol. 7 No. 4, 2002, pp. 311-324 (C)Henry Stewart Publications, $1465-4520$ 
phone appeals, others on special events, and many on a mix of different fundraising strategies. Some subsist on a large number of small contributions, while others rely on small numbers of large corporate, foundation or government grants. Some have professional staff dedicated to fundraising efforts, while others rely on programme and executive staff, volunteers, or board members. Some nonprofits hire out fundraising efforts to external professional fundraising firms, and others rely on federated drives or affiliated organisations for the bulk of their contributions. Approaches to fundraising are nearly as diverse as the types of organisations that populate the nonprofit sector, a fact that complicates efforts to understand how fundraising is achieved. This paper represents a modest effort to describe the ways that nonprofits organise themselves to generate grants and contributions for their organisations. It does not focus on the range of strategies that they use; rather, it considers the variety of people and institutional arrangements that nonprofits use to generate grants and donations.

The understanding of the formal organisation of fundraising has been hampered by lack of readily available and historically consistent information on fundraising efforts and their costs. Nonprofit organisations are required to report on fundraising efforts in their annual reports to the IRS (Form 990), but this information has been of limited use to researchers. Nonprofit organisations have some latitude in defining whether certain expenses count as programme, administrative, or fundraising expenses, and some nonprofits take more latitude than is suggested by IRS guidelines and generally accepted accounting principles. ${ }^{1}$ Research based on 1998 returns of Form $990^{2}$ indicates that 59 per cent of nonprofits receiving direct public contributions did not report any fundraising expenses, including nearly a quarter of those receiving more than $\$ 5 \mathrm{~m}$ in contributions. While 'zero-cost fundraising' frequently has legitimate explanations, ${ }^{2}$ the large number of nonprofits reporting no fundraising expenses limits Form 990 as a tool for understanding how US nonprofits do their fundraising.

This paper reports on new data from a national survey of nonprofit organisations to provide descriptive information about fundraising. The paper is in five sections. First, it introduces the idea of different fundraising domains and describes the research data. Secondly, it discusses the first domain, particularly staffing of fundraising activities in nonprofits and how volume of contributions is related to development staff size. Thirdly, it focuses on the second domain by considering the role of non-fundraising staff in fundraising activities, particularly the efforts of volunteers, board members and the executive director. Fourthly, it explores the third domain by describing the incidence of use of external relationships in fundraising activities, including the use of professional fundraising firms and interorganisational associations. Fifthly, it summarises results and offers a few conclusions.

\section{FUNDRAISING DOMAINS AND DATA TO STUDY THEM}

As indicated in the opening paragraphs of the paper, nonprofit organisations take advantage of a range of options when they consider how best to solicit funds for their organisations. The authors contend that the formal organisation of fundraising can be divided into three different domains, as illustrated in Figure 1. The first, indicated by the inner circle, is fundraising carried out as part of a nonprofit organisation's formal fundraising operations. This domain includes staff and consultants 
3. Nonprofit organisation's institutional environment
Figure 1 Three fundraising domains operating as staff whose primary function in the organisation is to generate grants and contributions. These staff members and others in the organisation think of these representatives as 'development' staff, and their activities are most likely to be represented in the organisation's financial reports as a fundraising expense.

The second domain, indicated by the larger circle and excluding the smaller one, is the nonprofit organisation's internal operations; staff and volunteers who do not think of themselves as development staff. Many organisations do not have staff whose primary responsibility is fundraising. Even among those that do, programme and administrative staff are frequently involved with grant writing, event planning and solicitation of contributions.

The third domain, indicated by the area outside the larger circle, is the nonprofit organisation's institutional environment. All nonprofits exchange resources with their institutional environments, and many develop relationships with other organisations as part of the means by which they acquire inputs necessary to carry out their programmes. Certainly the grant and contribution dollars raised by a nonprofit come from the institutional environment, but the environment itself can be a source of fundraising. One source is professional fundraising firms, who, for a fee, organise events or solicit contributions on behalf of nonprofit organisations. Another is federated fundraising organisations (such as the local United Way) and other partner organisations (such as a national headquarters, or a 'friends of group) that generate funds on behalf of a nonprofit organisation. Indeed, some nonprofits receive all of their contributions from one or more of the external elements represented by this domain.

To gain an understanding of these three fundraising domains, the authors undertook a survey of nonprofit organisations in the Fall (Autumn) of 2001. The tables and figures in this paper are based on a survey of 1,540 organisations selected from a list of US public charities. For details on the survey methodology, see the Appendix before the references section at the end of the paper. Tables 1 and 2 provide some descriptive statistics on the organisations in the study. Table 1 reports 
Table 1: Survey respondents by subsector

\begin{tabular}{lccc}
\hline & Frequency & $\begin{array}{c}\text { \% of survey } \\
\text { respondents }\end{array}$ & \% of population \\
\hline Arts, culture, humanities & 157 & 10 & 8 \\
Education & 224 & 15 & 13 \\
Health related & 212 & 14 & 15 \\
Human services & 536 & 35 & 34 \\
Public benefit and religion related & 177 & 11 & 10 \\
Environment/Animals/International/Unknown & 94 & 6 & 11 \\
Supporting & 140 & 100 & 100 \\
Total & 1,540 & & \\
\hline
\end{tabular}

Table 2: Survey respondents by categories of total grants/contributions

\begin{tabular}{|c|c|c|c|}
\hline & Frequency & $\begin{array}{l}\% \text { of survey } \\
\text { respondents }\end{array}$ & $\%$ of population \\
\hline No grants/contributions & 68 & 4 & 15 \\
\hline Less than $\$ 50,000$ & 353 & 23 & 16 \\
\hline$\$ 50,000-\$ 250,000$ & 481 & 31 & 31 \\
\hline$\$ 250,000-\$ 1 \mathrm{~m}$ & 372 & 24 & 22 \\
\hline more than $\$ 1 \mathrm{~m}$ & 265 & 17 & 15 \\
\hline Unknown & 1 & 0 & - \\
\hline Total & 1,540 & 100 & 100 \\
\hline
\end{tabular}

the breakdown of respondents by subsector. A third column is included to show how subsectors represented in this study are distributed in the nonprofit sector. Overall, the breakdown of survey respondents is very similar to the population distribution, ${ }^{3}$ although the 94 'Environment, Animals, International and Unknown' organisations (6 per cent of respondents) underrepresent the actual proportion of these organisations in the sector (11 per cent).

Table 2 reports the breakdown by level of grants and contributions reported by organisations in the survey. Grants and contributions include all private contributions from individuals, foundations and businesses, as well as grants from all levels of government. Table 2 is important because these categories of grant and contribution levels are used in many of the following tables. The study includes a small number of organisations that report no grants and contributions in their most recently completed fiscal year, although the respondents are either underrepresented in this category ${ }^{3}$ or were more willing to report small amounts of grants and contributions in the survey than they are on Form 990.

\section{FUNDRAISING DOMAIN 1}

\section{Fundraising staff}

While the use of staff dedicated to fundraising is not new to the US nonprofit sector, fundraising professionals 
Table 3: Full-time fundraising staff by categories of grants/contributions

\begin{tabular}{|c|c|c|c|c|c|}
\hline & \multicolumn{5}{|c|}{ Categories of total grants/contributions } \\
\hline & $\$ 0-\$ 50,000$ & $\begin{array}{l}\$ 50,000- \\
\$ 250,000\end{array}$ & $\begin{array}{l}\$ 250,000- \\
\$ 1 m\end{array}$ & $\begin{array}{l}\text { more than } \\
\$ 1 m\end{array}$ & Total \\
\hline No full-time fundraising staff & $81 \%$ & $72 \%$ & $55 \%$ & $30 \%$ & $63 \%$ \\
\hline One full-time fundraising staffer & $15 \%$ & $24 \%$ & $30 \%$ & $27 \%$ & $23 \%$ \\
\hline More than one full-time fundraising staffer & $4 \%$ & $4 \%$ & $15 \%$ & $43 \%$ & $14 \%$ \\
\hline
\end{tabular}

working for single organisations have traditionally been limited to the largest community organisations, including colleges, hospitals and museums. What is new is the diffusion of full-time and part-time fundraising staff to nonprofit organisations in all subsectors and of all sizes. 'Fund development' professionals have become a large and identifiable part of the nonprofit workforce, and an important part of many management teams. The Association of Fundraising Professionals, the professional organisation for nonprofit development professionals, claimed approximately 2,500 individual members in 37 chapters in 1980. By 2001, their membership had grown ten-fold, with more than 25,000 members in 163 chapters around North America, primarily in the USA.

To gain an understanding of how widespread the professionalisation of fundraising has become in nonprofit organisations, survey respondents were asked how many staff members or consultants their organisation employs whose primary responsibility is development or fundraising. Table 3 summarises how full-time, regular fundraising staff break down by categories of grants and contributions. The "no grants or contributions' and 'under $\$ 50,000$ in grants or contributions' categories have been combined since very few organisations have fundraising staff when they get no money from grants or contributions.

Despite the observations about the increasing presence of fundraising professionals in many nonprofit organisations in the USA, nearly two out of three organisations in the study (63 per cent) have no full-time regular staff members whose primary responsibility is fundraising. Even those organisations reporting more than $\$ 1 \mathrm{~m}$ in grants and contributions include almost one-third (30 per cent) without fundraising staff. What kinds of organisations attain this level of grants or contributions without a development staff? The authors consulted Form 990 for several representative organisations in this category to learn more about their circumstances. One organisation reported $\$ 25 \mathrm{~m}$ in government grants, but does not report the time and resources required to secure these grants as fundraising expenses. Consequently, this organisation reports no fundraising expenses, and has no fundraising staff. A second case fell into the 'more than $\$ 1 \mathrm{~m}$ in grants and contributions category' because it received a very large one-time government grant, a condition that did not require a full-time fundraiser and will not require one in the future. A third case is an international relief organisation that receives more than $\$ 1 \mathrm{~m}$ in direct contributions from individuals each year without the aid of dedicated fundraising staff. 
Table 4: Use of fundraising consultants by categories of grants/contributions

\begin{tabular}{|c|c|c|c|c|c|}
\hline & \multicolumn{5}{|c|}{ Categories of total grants/contributions } \\
\hline & $\$ 0-\$ 50,000$ & $\begin{array}{l}\$ 50,000- \\
\$ 250,000\end{array}$ & $\begin{array}{l}\$ 250,000- \\
\$ 1 m\end{array}$ & $\begin{array}{l}\text { more than } \\
\$ 1 m\end{array}$ & Total \\
\hline No consultant on fundraising staff & $93 \%$ & $87 \%$ & $78 \%$ & $74 \%$ & $84 \%$ \\
\hline One consultant on fundraising staff & $5 \%$ & $9 \%$ & $19 \%$ & $17 \%$ & $11 \%$ \\
\hline More than one consultant on fundraising staff & $2 \%$ & $5 \%$ & $3 \%$ & $8 \%$ & $4 \%$ \\
\hline
\end{tabular}

Note: Due to rounding up or down some of the columns in the table may not add up to $100 \%$

A little less than a quarter of nonprofits in the study ( 23 per cent) have one full-time person dedicated to fundraising. This number increases with increasing revenues from grants or contributions, except for those organisations with more than $\$ 1 \mathrm{~m}$ in grants or contributions. The largest size class is no more likely than less donor-rich nonprofits to have just one full-time fundraising staffer, but they are much more likely to have more than one such staffer. Despite the substantial number of large donative nonprofits with multiple fundraisers, however, the total number of nonprofits with more than one full-time fundraising staffer is quite low. Only 14 per cent of the nonprofits in the study have more than one full-time fundraiser, suggesting that the increasing professionalisation of fundraising is still rather concentrated in a small number of nonprofits.

Domain 1 also includes the practice of bringing contract workers inside the institutional boundary of the nonprofit organisation. Table 4 considers the practice of contracting fundraising expertise by hiring consultants to write grant proposals, organise special events and conduct other essentials of fund development. The survey results indicate that use of consultants is quite rare, with 84 per cent of respondents reporting that they employ no consultants whose primary responsibility is development or fundraising. Only 4 per cent of nonprofits in the study have more than one such consultant. Not surprisingly, the likelihood of such a condition is highest among organisations that receive the highest amount in grants and contributions.

Table 5 considers the use of any kind of fundraising staff, whether the dedicated staffer is full-time, part-time or hired as a consultant. A little less than half of the organisations in the study (45 per cent) have no staff whose primary responsibility is fundraising. As expected, the percentage of organisations with no fundraising staff declines as the organisation's total receipts from grants or contributions increase. Two out of three organisations with less than $\$ 50,000$ in grants and contributions have no fundraising staff, but less than one in five (17 per cent) organisations with at least $\$ 1 \mathrm{~m}$ in grants and contributions have no fundraising staff of any kind.

The percentage of nonprofits with one dedicated fundraising staffer does not differ much by category of total grants and contributions, ranging from one in four of the smallest and largest size classes to one in three of those organisations that receive $\$ 50,000-\$ 250,000$ in grants and contributions. However, size class is noticeably related to having more than one fundraising staffer. While a little over one-quarter of nonprofits have more than one full- 
Table 5: Full-time, part-time, or consultants as fundraising staff, by categories of grants/contributions

\begin{tabular}{|c|c|c|c|c|c|}
\hline & \multicolumn{5}{|c|}{ Categories of total grants/contributions } \\
\hline & $\$ 0-\$ 50,000$ & $\begin{array}{l}\$ 50,000- \\
\$ 250,000\end{array}$ & $\begin{array}{l}\$ 250,000- \\
\$ 1 m\end{array}$ & $\begin{array}{l}\text { more than } \\
\$ 1 m\end{array}$ & Total \\
\hline No fundraising staff & $66 \%$ & $49 \%$ & $36 \%$ & $17 \%$ & $45 \%$ \\
\hline One fundraising staffer & $24 \%$ & $34 \%$ & $30 \%$ & $24 \%$ & $28 \%$ \\
\hline More than one fundraising staffer & $10 \%$ & $17 \%$ & $34 \%$ & $59 \%$ & $27 \%$ \\
\hline
\end{tabular}

time, part-time or consultant dedicated to fundraising, only 10 per cent of organisations with less than $\$ 50,000$ in grants or contributions make this claim. In contrast, nearly three out of every five organisations with more than $\$ 1 \mathrm{~m}$ in grants and contributions have more than one fundraising staffer.

\section{FUNDRAISING DOMAIN 2}

\section{Non-fundraising staff involved in fundraising}

Executive directors frequently make appeals for support of their organisation, board members span organisational boundaries and serve as a conduit for major contributions, programme officers write grant proposals, and volunteers knock on doors, run, swim and bike for their neighbour's pledges. Clearly, not all fundraising in nonprofit organisations happens at the hands of professional fundraising staff. Those efforts comprise the second fundraising domain.

The authors asked organisations how much various organisational representatives are involved in fundraising efforts, ranging from a value of one if the group is not involved to a value of five if the group is extremely involved. The results of this question are in Figure 2, but the results for two different groups are presented. One group is organisations that said that their organisation has at least one staff member or consultant who is dedicated to fundraising (55 per cent of respondents in Table 5). The second group is the other 45 per cent that reported no such person.

Three conclusions can be drawn from Figure 2. First, on average, organisations with professional fundraising staff report that executive directors, board members, volunteers and other staff are more involved with fundraising than their counterparts in organisations with no professional fundraising staff. This finding reinforces a characterisation of two different approaches to fundraising: one set of organisations that relies on fundraising activities and demonstrates this by hiring professional staff, and another set of organisations that relies less on fundraising and has less need to call on its various constituencies to get it done.

Secondly, it was surprising to find that, on average, organisations with professional fundraising staff members characterise their executive director as more involved with fundraising than their fundraising staff. Clearly, the increasing professionalisation of the fund development field has not removed the executive director from the limelight of fundraising duties in 
Figure 2

Involvement in fundraising efforts

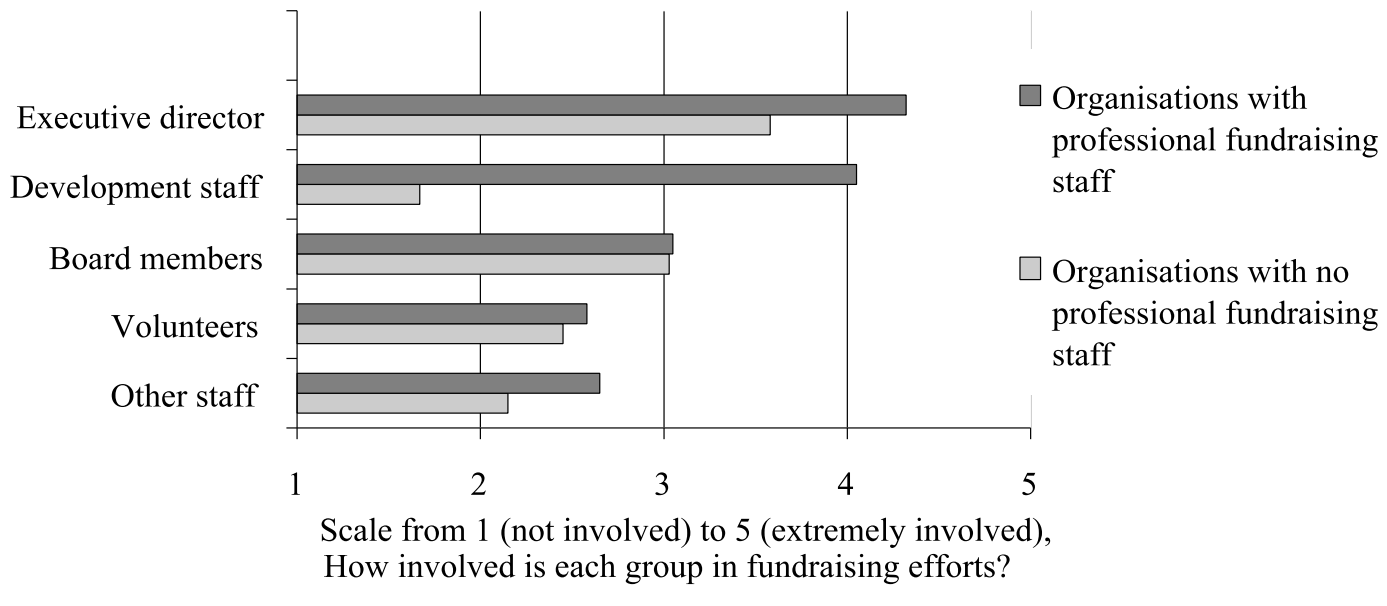

many nonprofit organisations. But in how many? In a separate question, survey respondents were asked what percentage of time the executive director and the fundraising staff spend on fundraising efforts. Nearly half of the organisation representatives (44 per cent) replied that their executive director spends no time on fundraising. A little more than half (53 per cent) said that the executive director spends some time, but less than half, on fundraising. The 3 three per cent indicated that the executive director spends more than half of his or her time on fundraising efforts. So, although the executive director does not spend the lion's share of his or her time raising funds, he or she is still seen as intimately involved with those efforts.

Thirdly, regardless of whether organisations have professional fundraising staff or not, a substantial portion count on the efforts of board members, volunteers and other staff to conduct fundraising. These people play a somewhat lesser role, but are a recognisable part of the second fundraising domain. To gain additional insights into the role of board members and other volunteers in raising funds, a few additional questions were asked about this. The first question was how many volunteers actively raise funds for the organisation, including board members and representatives of support organisations that are active fundraisers. Table 6 shows the relationship between different categories of volunteer use and categories of total grants and contributions. Three out of four organisations (74 per cent) in the study report using volunteers for fundraising. The increasing use of volunteers, however, is not linked in an obvious way to the amount of grants and contributions that an organisation brings in. While organisations that bring in more than $\$ 1 \mathrm{~m}$ in grants and contributions are somewhat more likely to use volunteers in fundraising efforts than those that bring in less than $\$ 50,000$, more volunteers are not generally associated with more grants and contributions. That is, the nonprofits in the lowest category of grants and contributions are no more or less likely to have one to five or six to 20 fundraising volunteers than nonprofits in the highest category. So, while use of volunteers is common, more volunteers do not necessarily mean more money.

Because volunteers are used as 
Table 6: Volunteer fundraisers by categories of grants/contributions

\begin{tabular}{|c|c|c|c|c|c|}
\hline & \multicolumn{5}{|c|}{ Categories of total grants/contributions } \\
\hline & $\$ 0-\$ 50,000$ & $\begin{array}{l}\$ 50,000- \\
\$ 250,000\end{array}$ & $\begin{array}{l}\$ 250,000- \\
\$ 1 m\end{array}$ & $\begin{array}{l}\text { more than } \\
\$ 1 m\end{array}$ & Total \\
\hline No volunteers & $39 \%$ & $18 \%$ & $23 \%$ & $22 \%$ & $26 \%$ \\
\hline $1-5$ volunteers & $18 \%$ & $26 \%$ & $18 \%$ & $17 \%$ & $20 \%$ \\
\hline $6-20$ volunteers & $26 \%$ & $32 \%$ & $34 \%$ & $26 \%$ & $30 \%$ \\
\hline $21-50$ volunteers & $10 \%$ & $16 \%$ & $15 \%$ & $23 \%$ & $15 \%$ \\
\hline 51-100 volunteers & $3 \%$ & $5 \%$ & $6 \%$ & $5 \%$ & $5 \%$ \\
\hline$>100$ volunteers & $4 \%$ & $3 \%$ & $4 \%$ & $7 \%$ & $4 \%$ \\
\hline
\end{tabular}

Table 7: Percentage of funds raised by volunteers, by categories of grants/contributions

\begin{tabular}{|c|c|c|c|c|c|}
\hline & \multicolumn{5}{|c|}{ Categories of total grants/contributions } \\
\hline & $\$ 0-\$ 50,000$ & $\begin{array}{l}\$ 50,000- \\
\$ 250,000\end{array}$ & $\begin{array}{l}\$ 250,000- \\
\$ 1 m\end{array}$ & $\begin{array}{l}\text { more than } \\
\$ 1 m\end{array}$ & Total \\
\hline None & $38 \%$ & $20 \%$ & $25 \%$ & $25 \%$ & $27 \%$ \\
\hline $10 \%$ or less & $17 \%$ & $27 \%$ & $30 \%$ & $34 \%$ & $26 \%$ \\
\hline $10-50 \%$ & $17 \%$ & $26 \%$ & $29 \%$ & $26 \%$ & $24 \%$ \\
\hline $50-99 \%$ & $13 \%$ & $15 \%$ & $10 \%$ & $10 \%$ & $12 \%$ \\
\hline All & $15 \%$ & $12 \%$ & $6 \%$ & $5 \%$ & $11 \%$ \\
\hline
\end{tabular}

fundraisers in different ways by different organisations, organisations in the study were asked what percentage of funds raised for their organisation is raised through the efforts of volunteers. Table 7 shows how several categories of the magnitude of volunteer fundraising vary by categories of grants and contributions. Consistent with Table 6, roughly one in four nonprofits say that volunteers play no role in their fundraising efforts. Roughly another quarter, however, say that volunteers are responsible for up to a tenth of the funds raised in the organisation, and another quarter say that volunteers are responsible for between 10 and 50 per cent of funds raised. The final quarter is split between organisations where volunteers are responsible for more than half or all of the fundraising responsibilities.

Also consistent with Table 6, percentage of funds raised by volunteers appears to have little association with the amount of grants or contributions flowing into a nonprofit organisation. organisations that bring in less than $\$ 50,000$ in grants or contributions are most likely to say that volunteers raise none of their contributions (38 per cent) and that volunteers raise all of their contributions (15 per cent). The other size classes differ little 
Table 8: Percentage of nonprofits that contracted with a professional fundraiser in previous year

\begin{tabular}{|c|c|c|c|c|c|}
\hline & \multicolumn{5}{|c|}{ Categories of total grants/contributions } \\
\hline & $\$ 0-\$ 50,000$ & $\begin{array}{l}\$ 50,000- \\
\$ 250,000\end{array}$ & $\begin{array}{l}\$ 250,000- \\
\$ 1 m\end{array}$ & $\begin{array}{l}\text { more than } \\
\$ 1 m\end{array}$ & Total \\
\hline Education & $6 \%$ & $9 \%$ & $20 \%$ & $21 \%$ & $12 \%$ \\
\hline Arts, culture, humanities & $11 \%$ & $5 \%$ & $13 \%$ & $25 \%$ & $10 \%$ \\
\hline Human services & $4 \%$ & $5 \%$ & $11 \%$ & $15 \%$ & $8 \%$ \\
\hline Public benefit & $6 \%$ & $0 \%$ & $7 \%$ & $10 \%$ & $5 \%$ \\
\hline Health & $4 \%$ & $2 \%$ & $3 \%$ & $2 \%$ & $3 \%$ \\
\hline All respondents & $5 \%$ & $5 \%$ & $10 \%$ & $12 \%$ & $8 \%$ \\
\hline
\end{tabular}

from each other and reflect the overall use of volunteers in fundraising efforts.

\section{FUNDRAISING DOMAIN 3}

\section{Inter-institutional arrangements}

Whereas the first two fundraising domains concern mobilisation of staff inside the boundaries of nonprofit organisations, the third domain concerns the mobilisation of external elements. This section focuses on two different kinds of formal arrangements that nonprofits enter into to help generate funds for their organisation. One is the engagement of professional fundraising firms, and the second is the cultivation of relationships with or creation of other bodies responsible for generating funds for nonprofits.

The first type of external fundraising relationship that is relevant for many nonprofits is contracting professional fundraising firms to solicit funds or hold special fundraising events on behalf of the organisation. Survey respondents were asked if their organisation had contracted with a professional fundraiser in their most recently completed fiscal year. Table 8 summarises the percentage of organisations that answered affirmatively to this question within several different nonprofit subsectors, and by category of total grants and contributions. Because subsectors with very few organisations provide unreliable estimates, only those subsectors are included for which there were at least 100 respondents.

Three conclusions can be drawn from Table 8 . First, only 8 per cent of nonprofits report use of external fundraising firms in their previous fiscal year. This number is conspicuously higher than the 5 per cent of nonprofits that reported professional fundraising fees on their 1999 Form $990,{ }^{3}$ suggesting that use of professional fundraisers does not always get reported as such. Still, the number indicates that a relatively small number of nonprofit organisations contract professional fundraising firms to help generate contributions.

Secondly, Table 8 indicates that use of professional fundraisers is more prevalent in some nonprofit subsectors than others. Without taking account of the category of total grants and contributions into which organisations fall, it can be observed that education nonprofits are four times more likely to hire a professional fundraising firm than health nonprofits.

Thirdly, it can be observed that an 
organisation's size class (that is, the category of total grants and contributions it falls into) plays a role in whether an organisation contracts with a professional fundraising firm or not, at least in some subsectors. Clearly, education and human service organisations with lower levels of grants and contributions are much less likely to hire a professional fundraising firm than their larger counterparts. This effect, however, is much less pronounced for public benefit organisations, and is nonexistent for health organisations. The largest arts, culture and humanities organisations are the most likely to contract a professional fundraiser, regardless of subsector. It can also be observed, however, that the organisations in this subsector that receive very small amounts of income from grants and contributions are also unusually likely (five of 45 like organisations in the study) to engage a professional fundraising firm.

The second type of institutional arrangement considered under fundraising Domain 3 is the cultivation of relationships with other organisations that fundraise on behalf of nonprofit organisations. Unlike professional fundraising firms with which nonprofits contract for specific services, the relationships identified here are between nonprofits and other nonprofittype organisations that act as fundraising agents. The survey asked about four specific relationships, as identified in Figure 3. First, organisations were asked if they receive money from federated campaigns, such as from the United Way or the Combined Federal Campaign. Secondly, they were asked if they received money from community or civic associations, such as a booster club, a church or a fraternal organisation. Thirdly, they were asked if they received money from a separately incorporated support organisation, such as an alumni association, an auxiliary organisation or a trust. Fourthly, they were asked if they received money from a parent organisation, such as a national office of a local hospital or university with which the nonprofit has close ties. To produce Figure 3 , the authors again divided respondents between those that have at least one dedicated fundraising staff member and those that do not.

Figure 3 shows that organisations that have a fundraising staff are also the kinds of organisations that are likely to receive money from Domain 3-type institutional affiliations, suggesting that such affiliations do not simply replace the need for fundraising staff. On the other hand, organisations with no fundraising staff are considerably more likely to receive money from at least one of these sources. On the whole, organisations with a fundraising staff are less likely to make use of these kinds of institutional affiliations; nonetheless, when they do make use of them, they are much more likely to make use of more than one.

Figure 3 also indicates that a substantial amount of fundraising activity takes place in these kinds of inter-institutional arrangements. In a separate question, respondents were asked what percentage of their total revenues they receive from this type of source. Half of the organisations in the study receive no money from this kind of source, and roughly a quarter receive less than 10 per cent of their revenues from external fundraising relationships. Approximately 15 per cent of nonprofits receive more than 10 per cent, but less than half, of their revenues from these kinds of funding arrangements. Less than 1 per cent of organisations in the study say that they receive all of their revenues from these sources.

\section{DISCUSSION}

Based on a relatively large sample of nonprofits of various sizes and subsec- 
Figure 3

Percentage of nonprofits that receive money from various external stakeholders

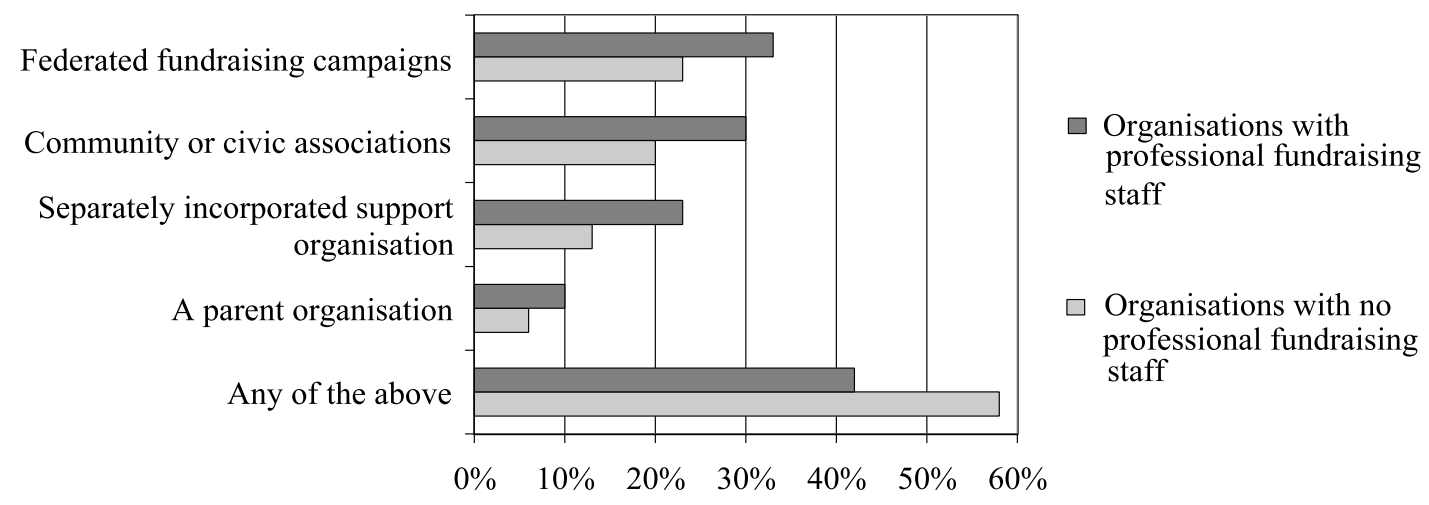

Percentage of organisations that receive money from a particular source

tors, the authors have been able to glean domains and patterns about how nonprofits accomplish their fundraising. First, despite a growing trend by nonprofit organisations to hire fundraising professionals as part of their permanent staff, most nonprofits (63 per cent) do not have a full-time fundraising staff person. Not surprisingly, nonprofits with more than one fundraising staffer are concentrated among those organisations with more than $\$ 1 \mathrm{~m}$ in annual grants and contributions. Even when considering any kind of internal fundraising staff (full-time, part-time, or hired consultants), most small nonprofits do not have any representatives who spend most of their time on fundraising activities. In contrast, the majority of organisations with more than $\$ 1 \mathrm{~m}$ in annual grants and contributions have more than one such person.

In addition to dedicated fundraising professionals, the authors also considered a second domain of other nonprofit staff who do fundraising in the course of their other duties. While the executive directors in most nonprofits are reported to be fairly involved with fundraising, they are more involved, on average, in those organisations where there is also a fundraising staff person present. Similarly, volunteers and other staff are more involved with fundraising when there is a development staff person; in contrast, board members are equally involved regardless of development staffing. The pronounced role of the executive director, other staff members, and volunteers in fundraising in organisations with fundraising professionals is striking since one might expect that the fundraising professional would relieve the need for others to be involved with raising funds. On the other hand, since fundraisers often involve volunteers and other staff in their efforts, one should not be surprised at the increased presence of volunteers among those organisations with professional fundraising staff. In any case, it appears that organisations that are serious enough about fundraising to hire a fundraising staffer are also those organisations where the fundraising responsibilities are infused throughout the organisation. Further, the presence of an internal fundraising professional may serve as an impetus for moving the 
fundraising agenda forward and keeping it on the radar screen for the executive director and others.

In addition to fundraising efforts by people inside nonprofit organisations, the authors also considered a third domain of fundraising consisting of fundraising by external allies. One of the more conspicuous findings is the concentration of professional fundraiser contracts among organisations that raise moderate $(\$ 250,000-\$ 1 \mathrm{~m})$ and larger (more than $\$ 1 \mathrm{~m}$ ) sums of money each year, and in the education, arts and human services subsectors. The larger organisations in these subsectors were between two and three times more likely to contract with a professional fundraising firm in the past year, compared with the overall sample. Finally, the authors noted substantial numbers of inter-organisational relationships that result in fundraising windfalls for nonprofit organisations. Over half of nonprofits with no fundraising staff and two in five with fundraising staff reported receiving contributions from a federated campaign, a community or civic association, a parent organisation, or a support organisation.

In addition to shedding some light on these three different domains of fundraising, this paper demonstrates the complexity and heterogeneity of fundraising structure and strategy in the nonprofit sector. It also begins to give some insights into why some nonprofits might report fundraising revenues without concomitant fundraising costs. The zerofundraising costs question is an issue that invites additional future research.

\section{APPENDIX}

In the Fall of 2001, the authors drew a sample of organisations from the year 2000 Core File developed by the $\mathrm{Na}-$ tional Center for Charitable Statistics (NCCS). The Core Files combine descriptive information from the IRS Business Master Files and financial variables from the Return Transaction Files, representing the best available sampling frame of nonprofit organisations in the USA. Several kinds of organisations were excluded from the sampling frame before the sample was drawn. First, since the authors wanted to focus on organisations that were sufficiently large to have a fundraising structure, organisations that were selected reported at least $\$ 100,000$ in gross receipts.

Secondly, the sample was restricted to charities that operate most like traditional community nonprofit organisations. Organisations were eliminated that use coded as mutual or membership benefit organisations, pension and retirement funds, real estate organisations, and named foundations or trusts that are not elsewhere classified as a foundation. The authors scanned organisations with the word 'Trust' in their name and used their judgment about whether they should be included or not. In truly ambiguous cases, Form 990 was consulted to see how organisations represented their programmes. The resulting sampling frame was stratified by organisational subsector, several categories of total revenues and whether or not they reported fundraising expenses. Samples were drawn randomly within these strata, proportional to the number of organisations in each grouping.

During the Fall of 2001, the authors gathered phone numbers from published sources and attempted pre-mailing calls with 3,782 sampled organisations. The goal was to verify the organisation mailing address and get the name of the appropriate contact in each nonprofit, to discuss the project briefly with this person, and to alert him or her to the 
imminent arrival of the survey. The authors were able to complete pre-calls with 3,115 organisations and successfully deliver the survey to 3,082. The survey process following the pre-call included Federal Express delivery of a survey, cover letter and return envelope; a reminder postcard to nonrespondents after two weeks; and a second full mailing of the survey by US Mail after an additional two weeks. In the second mailing, each respondent was given a unique username and password to access an Internet version of the survey. After an additional three weeks, each nonrespondent was called at least once. By the end of the study period, the authors had received 1,540 valid surveys (50 per cent).

\section{References}

(1) Brostek, M. (2002) 'Tax-exempt organisations: Improvements possible in public, IRS, and state oversight of charities', US General Accounting Office, Washington, DC.

(2) Cordes, J. J. and Wilson, S. (2000). 'Costless fundraising: Deconstructing the evidence', Paper presented at the annual meeting of the Association for Research on Nonprofit organisations and Voluntary Action, New Orleans, Louisiana.

(3) Independent analysis of Forms 990 for 1999, authors. 